\section{Only high disease activity and positive rheumatoid factor indicate poor prognosis in patients with early rheumatoid arthritis treated with "sawtooth" strategy}

\author{
T Möttönen, L Paimela, M Leirisalo-Repo, H Kautiainen, J Ilonen, P Hannonen
}

Division of Rheumatology, Department of Medicine, Turku University Central Hospital, Turku, Finland

T Möttönen

\section{Department of} Rheumatology, Malmi Hospital, Helsinki, Finland

L Paimela

Division of Rheumatology, Department of Medicine, Helsinki University Central Hospital, Helsinki, Finland

M Leirisalo-Repo

MedCare Oy, Äänekoski, Finland $\mathrm{H}$ Kautiainen

Department of Virology, Turku University, Turku, Finland

J Ilonen

Department of Medicine, Jyväskylä Central Hospital, Jyväskylä, Finland P Hannonen

Correspondence to: Dr T Möttönen, Turku University Central Hospital, Division of Rheumatology, Paimio Hospital, FIN-21540 Paimio, Finland.

Accepted for publication 16 July 1998

\begin{abstract}
Objectives-To investigate the prognostic significance of clinical and genetic markers on the outcome of patients with recent-onset rheumatoid arthritis (RA) treated actively with slow acting antirheumatic drugs (SAARDs).

Methods-A total of 142 consecutive patients with early RA (median disease duration of 7 months) were treated according to the "sawtooth" strategy and prospectively followed up for an average of 6.2 years. Several clinical parameters at start as well as genetic markers were related to the functional outcome (ARA Functional class and HAQ disability score) and radiographic joint damage (Larsen's score) at the latest visit.

Results-In logistic regression analysis only Mallya score (including morning stiffness, pain scale, grip strength, Ritchie's articular index, haemoglobin, and erythrocyte sedimentation rate) at baseline, and Mallya score and rheumatoid factor (RF) positivity at one year were found to be of significance with respect to the radiographic outcome of the patients. Furthermore, at the latest visit HAQ score was related to radiographic score. At baseline the mean ages of the DR4 positive patients and the patients with RA associated DR alleles were statistically significantly lower than those without the above mentioned risk factors (44 v 49, $\mathrm{p}=0.03$ and $41 v 53, p=0.04$, respectively). However, these genetic markers had no prognostic significance on the functional or radiographic outcome of the patients.

Conclusion-High clinical disease activity at baseline and RF positivity especially at one year after the institution of SAARD treatment are the best predictors of poor prognosis in early RA. However, from the clinical point of view, the disease outcome of an individual patient with early RA, cannot be predicted accurately enough by present means.

(Ann Rheum Dis 1998;57:533-539)
\end{abstract}

Rheumatoid arthritis (RA) is an autoimmune disorder with unknown cause and characterised by a varying course of the disease. Early RA rarely remits spontaneously but in most cases the disease shows a resistant course with progressive joint damage and disability. ${ }^{1-3}$ Slow acting antirheumatic drugs (SAARDs) may change the short-term course of RA. ${ }^{4-7}$ However, more effective treatments are needed and new strategies for the SAARD treatments have been suggested. ${ }^{8} 9$

Optimal management of RA requires early diagnosis and immediate aggressive treatment. ${ }^{10}$ The costs of new antirheumatic treatments in the future may be high, and only a proportion of the patients will probably have the best benefit from the treatment. Thus, there is an obvious need to develop methods to identify the rapidly deteriorating patients and to save others from toxic or expensive treatments, or both.

Numerous clinical and laboratory indices have been tested as predictive outcome markers but the results have been neither convincing nor consistent. ${ }^{11-16}$ Genetic susceptibility markers have been claimed to be able to predict persisting arthritis, but their role as markers for disease severity in established disease has remained conflicting. ${ }^{17-23}$ The controversies may be caused by the differences in the selection of patients, variations in the duration of disease, and in the designs of the studies. ${ }^{12} 24$ Furthermore, active use of SAARDs as early treatment may have influenced the results.

We have recently found that the outcome of 142 patients with early RA after a mean of 6.2 years was widely variable. During the study, each patient was treated with SAARDs according to the set of principles for "sawtooth" strategy - that is, (1) SAARD treatment was begun early; (2) the use of one or multiple SAARDs was virtually uninterrupted; (3) if no positive effect could be established during 3-6 months or if an initial adequate effect disappeared or a clinically meaningful untoward adverse effect occurred, the SAARD was replaced with another one. ${ }^{9}$ Despite the treatment strategy, one quarter of the patients failed to respond and deteriorated to ARA Functional classes III-IV and Health Assessment Questionnaire (HAQ) disability score > 1. On the other hand, one third of the patients were in remission at the end of the follow up. ${ }^{25}$

In this paper we have further tested the prognostic significance of clinical and genetic factors and the impact of SAARD treatment on the functional outcome and radiographic joint destruction in the cohort of early RA patients. In addition, the relations between the clinical disease activity, structural joint damage, and functional disability of these patients were examined. 
Table 1 Clinical data of the patients in this study enrolled originally in two separate cohorts

\begin{tabular}{lll}
\hline & Cohort 1 (Möttönen) & Cohort 2 (Paimela et al) \\
\hline Patients (n) & 57 & 85 \\
Age, median (range) & $50(17-79)$ & $46(19-65)$ \\
Female/male, \% & $68 / 32$ & $80 / 20$ \\
Disease duration at entry, months, median & $7(2-24)$ & $8(2-12)$ \\
$\quad$ (range) & 58 & 67 \\
Rheumatoid factor found at entry, \% & 56 & 64 \\
HLA-DR4 present, \% & $2.7(1.5-3.7)$ & $2.5(1.3-3.6)$ \\
Mallya score at entry, median (range) & $0(0-28)$ & $2(0-22)$ \\
Larsen's score at entry, median (range) & & $60(36-84)$ \\
Followup period at the latest visit, months, & $91(18-111)$ & 100 \\
$\quad$ median (range) & 100 & 12 \\
\% Treated with SAARDs during the study & & 5 \\
Maximum symptomatic time before the start of & 24 & \\
$\quad$ SAARD treatment, months & 5 & \\
Patients with joint replacements during the study & 5 & \\
\hline
\end{tabular}

\section{Methods}

The study population consisted of 142 consecutive early RA patients of white origin (107 women, 35 men, median disease duration of 7 months) enrolled in two separate cohorts. The inclusion criteria included symptoms of RA less than 24 months and no previous SAARD and systemic corticosteroid treatment. The patients were referred to specialists from primary health care centres or private outpatient clinics. During the study period, all patients met the American College of Rheumatology (ACR) 1987 criteria for RA. ${ }^{26}$ Initially, the two cohorts were assembled to study the early erosiveness of recent onset RA. ${ }^{27}{ }^{28}$ Table 1 shows the clinical data of the patients included in this study. The patients older than 65 years of age were excluded from the cohort $\left.2^{28}\right)$. Most importantly, all the patients in both groups were treated in the same country and with continuous use of SAARDs from the beginning of the study. Subsequently, the patients were combined in this prospective, longitudinal study. A more detailed description of the patients has been reported previously. ${ }^{25}$

Patients were followed up for a mean of 6.2 years (range 1.5-9.2, SD 1.6 years); 133 (94\%) patients have been followed up for at least five years, and $84(59 \%)$ for at least six years.

Clinical variables of disease activity were assessed at study entry and thereafter at intervals of 6-12 months. The count of swollen (66 joints) and tender (68 joints) joints and the index of disease activity (Mallya score) ${ }^{29}$ were recorded at entry and after one year. The Mallya score includes two subjective measures (morning stiffness, pain scale), two semi- objective measures (grip strength, Ritchie articular index ${ }^{30}$ ), and two objective measures (haemoglobin, erythrocyte sedimentation rate (ESR)). Remission was defined according to the ACR preliminary criteria for clinical remission, but duration criterion was excluded. Thus the frequency of remissions represent the cross sectional situation. ${ }^{31}$

Posteroanterior radiographs of both hands, wrists, and feet were obtained at entry, once a year for the next two years, and at the end of the follow up. Serial radiographs were read by the same experienced rheumatologists. The number of eroded joints were counted and radiographs were scored according to the method introduced by Larsen and coworkers. ${ }^{32}$

The development of patients functional disability was assessed by the ARA Functional class $^{33}$ and by the HAQ disability indices. ${ }^{34}$

\section{LABORATORY EXAMINATIONS}

$\mathrm{RF}$ was determined at onset, and at one and two years by the Waaler-Rose test; titres $>1: 64$ were regarded as positive. The presence of HLA-DR1 and -DR4 including subspecificities associated with RA susceptibility was defined by combining serological and cellular typing methods. HLA-DR typing was performed in 140 patients by standard microlymphocytotoxicity test using commercial panels of antisera (Biotest AG, Dreieich, Germany). HLA-DR4 subspecificities Dw4 and Dw14 corresponding DRB $1^{\star} 0401$ and $\mathrm{DRB} 1{ }^{\star} 0404 /$ 0408 alleles were defined in the cohort 1 (57 consecutive patients) using homozygous typing cells in mixed lymphocyte cultures as described earlier. $^{35}$

\section{STATISTICAL ANALYSIS}

Outcome variables were assessed using the end point analysis. The prognostic value of the demographic and clinical features studied at the onset of the follow up and the genetic markers were related to several measures of outcome as determined at the latest visit. Outcome variables analysed included ARA Functional class, HAQ disability score, remission, and Larsen's score. Descriptive values of the variables with a normal (Gaussian) distribution were expressed as means and standard deviations (SD); statistical comparison between the groups was performed by using $t$ test or analysis of variance (ANOVA). If the variables did not have a Gaussian distribution or they were

Table 2 The presence of HLA DR4 in 140 patients and shared epitopes (SE) in 57 patients with early RA and the course of RA

\begin{tabular}{|c|c|c|c|c|c|c|c|}
\hline & \multicolumn{2}{|l|}{$H L A D R 4$} & \multirow[b]{2}{*}{$p$ Value } & \multicolumn{3}{|l|}{$S E$} & \multirow[b]{2}{*}{$p$ Value } \\
\hline & $\begin{array}{l}\text { Not found } \\
(n=55)\end{array}$ & $\begin{array}{l}\text { Found } \\
(n=85)\end{array}$ & & $\begin{array}{l}\text { No SE found } \\
(n=12)\end{array}$ & $\begin{array}{l}\text { Single } S E \text { found } \\
(n=25)\end{array}$ & $\begin{array}{l}\text { Double dose of SE } \\
\text { found }(n=20)\end{array}$ & \\
\hline \multicolumn{8}{|l|}{ At the onset } \\
\hline age, year, mean (SD) & 49 (13) & $44(14)$ & 0.029 & $53(10)$ & $51(17)$ & $41(15)$ & 0.042 \\
\hline disease duration, months, median (range) & $6(2-24)$ & $8(2-20)$ & NS & $6.5(3-24)$ & $7(2-18)$ & $7(2-20)$ & NS \\
\hline rheumatoid factor positivity, $\%$ & 58 & 66 & NS & 33 & 64 & 65 & NS \\
\hline swollen joint count, median (range) & $6(1-35)$ & $5(1-30)$ & NS & $13(1-34)$ & $8(1-35)$ & $9.5(1-20)$ & NS \\
\hline tender joint count, median (range) & $16(3-40)$ & $15(2-36)$ & NS & $22.5(8-37)$ & $17(3-40)$ & $13.5(4-30)$ & NS \\
\hline Mallya score, median (range) & $2.6(1.6-3.7)$ & $2.5(1.3-3.6)$ & NS & $2.8(1.7-3.5)$ & $2.7(1.7-3.7)$ & $2.2(1.5-3.0)$ & 0.047 \\
\hline Larsen score, median (range) & $0(0-27)$ & $2(0-28)$ & NS & $0(1-16)$ & $0(0-28)$ & $0(0-11)$ & NS \\
\hline \multicolumn{8}{|l|}{ At the latest visit } \\
\hline In remission, $(\%)$ & 31 & 32 & NS & 33 & 32 & 40 & NS \\
\hline Larsen score, median (range) & $28(0-180)$ & $39(0-146)$ & NS & $59(11-123)$ & $41(0-180)$ & $47.5(4-146)$ & NS \\
\hline with nodules, $(\%)$ & 15 & 11 & NS & 17 & 12 & 15 & NS \\
\hline SAARDs used, median (range) & $3(1-7)$ & $3(1-8)$ & NS & $4(1-7)$ & $3(1-8)$ & $4(1-8)$ & NS \\
\hline
\end{tabular}


Table 3 Rheumatoid factor (RF) seropositivity and prognosis of 142 patients with early $R A$ during the follow up period of a mean of six years

\begin{tabular}{|c|c|c|c|c|c|c|c|c|c|}
\hline & \multicolumn{3}{|l|}{$R F$ at baseline } & \multicolumn{3}{|l|}{$R F$ at one year } & \multicolumn{3}{|c|}{$R F$ at baseline and one year } \\
\hline & $R F+(n=90)$ & $R F-(n=52)$ & $p$ Value & $R F+(n=76)$ & $R F-(n=66)$ & $p$ Value & $R F+(n=62)$ & $R F-(n=38)$ & $p$ Value \\
\hline \multicolumn{10}{|l|}{ At onset } \\
\hline $\begin{array}{l}\text { swollen joint count, } \\
\text { median (IQR) } \\
\text { tender joint count, median }\end{array}$ & $5(3-10)$ & $5.5(2-14)$ & NS & $6(4-14)$ & $3(2-7)$ & $<0.001$ & $6(4-12)$ & $4(2-8)$ & NS \\
\hline $\begin{array}{l}\text { (IQR) } \\
\text { Mallya score, median }\end{array}$ & $15(8-21)$ & $16(9-24)$ & NS & $16(9-24)$ & $13.5(8-20)$ & NS & $16(8-24)$ & $15(7-24)$ & NS \\
\hline (IQR) & $2.4(2.1-2.8)$ & $2.6(2.2-3.0)$ & NS & $2.5(2.1-2.8)$ & $2.4(2.1-2.8)$ & NS & $2.5(21-28)$ & $2.6(2.1-3.0)$ & NS \\
\hline $\begin{array}{l}\text { At one year } \\
\text { swollen joint count, }\end{array}$ & \multicolumn{5}{|c|}{ At one year } & $<0001$ & $2(0-7)+2$ & $0(0-2)$ & 001 \\
\hline $\begin{array}{l}\text { Mallya score, median } \\
\text { (IOR) }\end{array}$ & $1.8(1.5-2.1)$ & $1.8(1.5-2.4)$ & NS & $2.0(1.5-2.5)$ & $1.8(1.3-2.2)$ & 0.011 & $2.0(1.5-2.5)$ & $1.8(1.3-2.3)$ & NS \\
\hline At two year & & & & & & & $2.0(1.5-2.5)$ & $1.0(1.3-2.3)$ & $1 \mathrm{No}$ \\
\hline $\begin{array}{l}\text { in remission, } \% \\
\text { At the latest visit }\end{array}$ & 24 & 33 & NS & 17 & 39 & 0.003 & 19 & 42 & 0.014 \\
\hline $\begin{array}{l}\text { nodules found, } \% \\
\text { ARA Functional Class }\end{array}$ & 14 & 8 & NS & 22 & 0 & $<0.0001$ & 21 & 0 & 0.002 \\
\hline III-IV, \% & 28 & 17 & NS & 36 & 11 & $<0.001$ & 36 & 11 & 0.006 \\
\hline $\mathrm{HAQ}>1, \%$ & 22 & 26 & NS & 27 & 19 & NS & 27 & 25 & NS \\
\hline in remission, $\%$ & 29 & 37 & NS & 26 & 38 & NS & 27 & 42 & NS \\
\hline $\begin{array}{l}\text { SAARDs used, median } \\
\text { (IQR) }\end{array}$ & $3(1-5)$ & $3(2-5)$ & NS & $4(2-5)$ & $2(1-4)$ & 0.0066 & $3(2-5)$ & $2(1-4)$ & NS \\
\hline $\begin{array}{l}\text { Discontinuations of SAARD } \\
\text { treatment because of } \\
\text { inefficacy, median (IQR) }\end{array}$ & $1(0-2)$ & $0.5(0-3)$ & NS & $1.5(0-3)$ & $0.5(0-2)$ & 0.013 & $1(0-2)$ & $0(0-2)$ & 0.022 \\
\hline
\end{tabular}

HAQ = Health Assessment Questionnaire.

ordinal, then descriptive values were expressed as medians and interquartile ranges (IQR) or ranges; statistical comparison between the groups was performed by using Mann-Whitney or Kruskal-Wallis tests. Measures with a discrete distribution were expressed as counts (\%) and analysed by $\chi^{2}$ or Fisher's exact test.
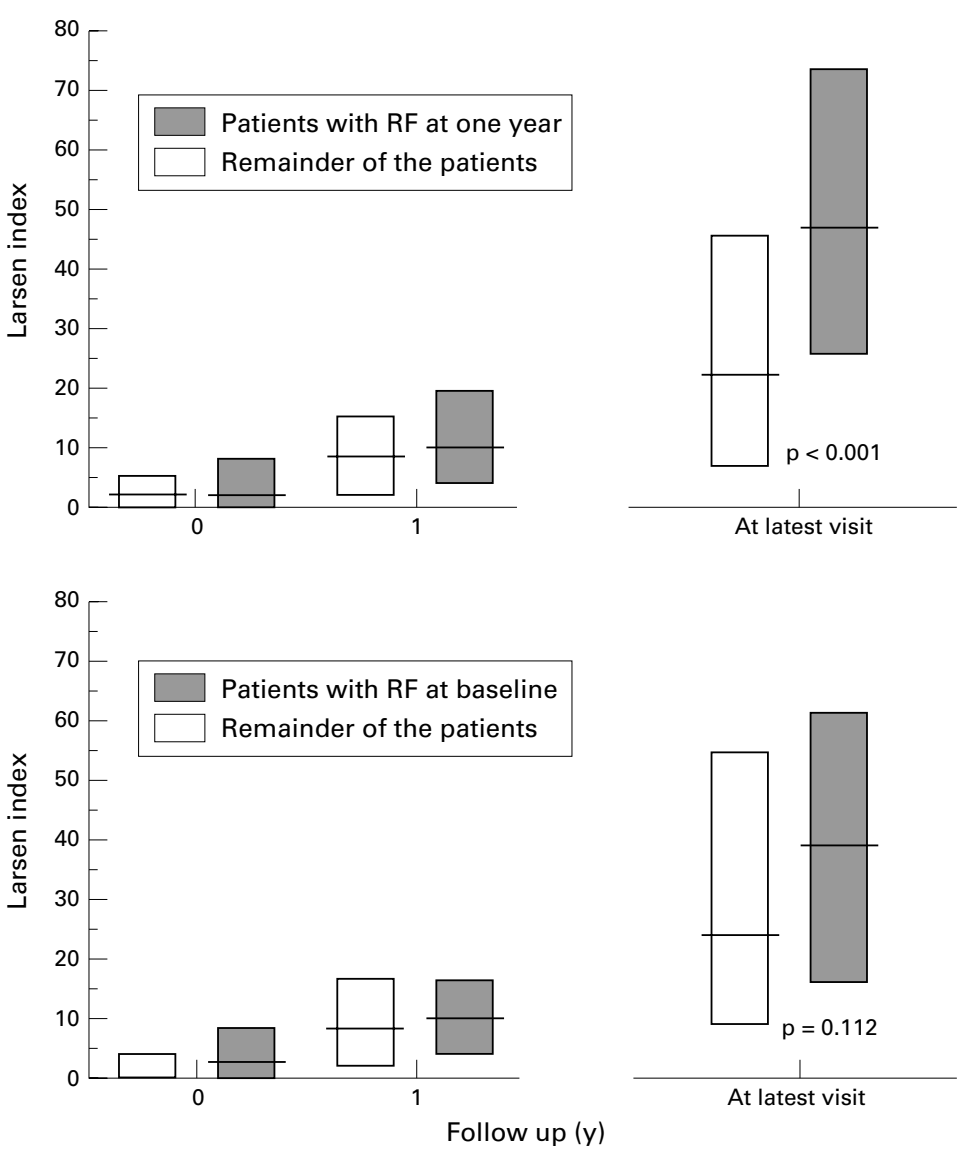

Figure 1 Larsen's score over time in the seronegative and seropositive patients followed up for a median of seven years and $R F$ detected at baseline and at one year. Horizontal bars indicate the median values; boxes indicate the first through third quartiles.
The normality of variables was evaluated by the Kolmogorov-Smirnov statistics, with a Lilliefors significance or Shapiro-Wilk statistics. No adjustment was made for multiple testing, but this information can be obtained by multiplying the actual $p$ value by the number of comparison made. Correlations were estimated with Spearman's correlation coefficient method. For estimation of prediction we used a logistic regression model and determined which variables at entry and at one year were predictive for the most progressive joint destruction. Because $34 \%$ of the patients (48 of 142) had deteriorated to Larsen's score more than 50 at the latest visit, we chose to compare them with the remaining two thirds of the cases and used in the analysis that cut off point.

\section{Results}

EFFECT OF SEX ON OUTCOME

Disease remission at the latest visit was observed more frequently in men (54\%) than in women $(24 \%)(\mathrm{p}<0.01)$. No significant differences were found between the sexes in the values of disease duration or clinical activity of RA at baseline. However, in the men without remission the course of RA was more severe than in the women on average. No significant difference was observed between the sexes in median values of the final Larsen's and HAQ scores, in the number of SAARDs used during the follow up, or in the frequencies of the patients with nodular disease.

EFFECT OF AGE ON OUTCOME

At baseline 118 patients ( $83 \%$ ) were $<60$ and $24(17 \%)>60$ years of age. The median (IQR) Mallya and Larsen's scores were significantly higher at baseline in the older patient group than in the younger one $(2.8,(2.3-3.0) v 2.5$, (2.1-2.8); $\mathrm{p}=0.01$ and $4(0-14) \cup 2,(0-5)$; $\mathrm{p}=0.0007$, respectively). Despite the comparable intensity of SAARD treatment and in the rate of achieved remissions the older patients 
Table 4 Baseline characteristics and clinical data in the patients with slow and fast rate of radiographic progression during follow up period of a mean of six years. Cut off point $>50$ (fast) and $\geqslant 50$ (slow) Larsen score at the latest visit

\begin{tabular}{|c|c|c|c|}
\hline & \multicolumn{2}{|l|}{ Radiographic progression } & \multirow[b]{2}{*}{$p$ Value } \\
\hline & Slow (Larsen score $\leqslant 50$ ) & Fast (Larsen score $>50$ ) & \\
\hline Patients (n) (\%) & $94(66)$ & $48(34)$ & \\
\hline \multicolumn{4}{|l|}{ At onset } \\
\hline age, year, mean (SD) & $46(13)$ & $44(14)$ & NS \\
\hline disease duration, months, median (IQR) & $8(5-11)$ & $6(4-9)$ & NS \\
\hline female/male, $\%$ & $73 / 27$ & $79 / 21$ & NS \\
\hline RF positivity, \% & 60 & 70 & NS \\
\hline DR4 positivity, \% (studied in 140 patients) & 63 & 55 & NS \\
\hline DRB $1{ }^{\star} 0101 /{ }^{\star} 0401 / 4 / 8$ positivity, $\%$ (studied in 57 patients) & 84 & 72 & NS \\
\hline swollen joint count, median (IQR) & $4(2-8)$ & $7(3-14)$ & 0.015 \\
\hline tender joint count, median (IQR) & $14.5(7-22)$ & $16.5(12-23)$ & NS \\
\hline ESR, median (IQR) & $25.5(14-52)$ & $35(24-55)$ & 0.033 \\
\hline Mallya score, median (IQR) & $2.3(2.1-2.8)$ & $2.8(2.4-3.0)$ & $<0.001$ \\
\hline HAQ score, median (IQR) (studied in 134 patients) & $0.1(0-0.4)$ & $0.3(0.1-0.5)$ & $<0.001$ \\
\hline Larsen score, median (IQR) & $2(0-7)$ & $2(0-8)$ & NS \\
\hline \multicolumn{4}{|l|}{ At the latest visit } \\
\hline disease duration, median (IQR) & $76(60-84)$ & $84(60-95)$ & 0.01 \\
\hline HAQ score, median (IQR) (studied in 130 patients) & $0(0-0.5)$ & $1.0(0.5-1.8)$ & $<0.001$ \\
\hline SAARDs used, median (IQR) & $2(1-4)$ & $5(4-6)$ & $<0.001$ \\
\hline \multicolumn{4}{|l|}{ SAARDs discontinuations } \\
\hline because of inefficacy, median (IQR) & $0(0-1)$ & $3(2-3)$ & $<0.0001$ \\
\hline because of adverse event, median (IQR) & $0(0-1)$ & $1(0-2)$ & 0.0036 \\
\hline
\end{tabular}

HAQ = Health Assessment Questionnaire.

developed more often a nodular disease $(29 \% v$ $9 \%, \mathrm{p}=0.01$ ) and progressed more often to ARA Functional classes III-IV than the younger patients $(42 \% v 20 \%, \mathrm{p}=0.026)$. At the latest visit also the median (IQR) Larsen's score was significantly higher in the older patients than in the younger patients (42.5, (27-84) v 30, $(11-59) ; p=0.004)$. However, in logistic regression analysis age was not found to be a significant predictor of further joint damage.

EFFECT OF SYMPTOMATIC PERIOD AT STUDY ENTRY ON OUTCOME

In 62 patients $(44 \%)$ the time period between symptoms at onset and institution of SAARD treatment was less than six months. At the baseline the median (IQR) Mallya score of these patients was significantly higher (2.8, $(2.3-3.0))$ than that of the rest of the patients $(2.3,(2.0-2.8))(p=0.002)$. However, at one year the clinical disease activity was comparable in both patient groups. The number of RF positive patients at baseline, as well as those with HLA-DR4 or some of the alleles with the so called "shared epitope" (SE) were also found in comparable frequencies in both groups. The relatively short delay in the institution of SAARD treatment at baseline did not influence the further response to the treatment, the development of joint destructions or the rate of remissions (data not shown).

Table 5 Logistic regression analysis with total radiographic progression Larsen score more than 50 at the latest visit in 140 early $R A$ patients treated with "sawtooth" strategy for a mean of six years

\begin{tabular}{lll}
\hline & \multicolumn{2}{l}{ Model } \\
\cline { 2 - 3 } Variable & $\begin{array}{l}\text { At onset } \text { OR } \\
(95 \% \text { CI })^{*}\end{array}$ & $\begin{array}{l}\text { At one year } \text { OR } \\
\text { (95\% CI) }\end{array}$ \\
\hline Sex (female) & $1.7(0.7$ to 4.5$)$ & $2.3(0.8$ to 6.2$)$ \\
Age ( $\geqslant 60)$ & $1.5(0.5$ to 4.1$)$ & $1.3(0.4$ to 3.8$)$ \\
DR4 found & $0.7(0.3$ to 1.7$)$ & $0.8(0.4$ to 1.8$)$ \\
RF positivity & $2.3(1.0$ to 5.3$)$ & $3.9(1.7$ to 9.2$)$ \\
Mallya score & $4.7(2.0$ to 11.0$)$ & $2.8(1.4$ to 5.6$)$ \\
Presence of erosion & $0.9(0.4$ to 2.1$)$ & - \\
Disease duration (months) at the latest visit & $1.0(0.9$ to 1.1$)$ & $1.0(0.9$ to 1.1$)$ \\
\hline
\end{tabular}

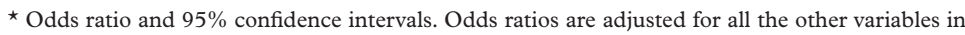
the model.
EFFECT OF HLA DR1- AND DR4-ALLELES AND SHARED EPITOPE ON OUTCOME

At baseline the mean age of the DR4 positive patients and of the patients with a double dose of SE was lower than in the rest of the patients (table 2). The frequencies of DR1- and DR4-alleles and SE were comparable in women and men (data not shown).

The presence of DR4-allele or SE had no significant influence on the rate of achieved remissions, the development of joint damage, or a nodular disease, or on the number of SAARDs used during the follow up (table 2). Furthermore, none of the patients with joint replacement had a double dose of SE and most of these patients were without any SE.

EFFECT OF RF ON OUTCOME (TABLE 3)

The genetic markers (HLA-DR1, -DR4, SE) were not related to the presence or absence of RF at any time point during the study (data not shown). At start of the study RF was found in $71 \%$ of the women and $61 \%$ of the men, but at one year men were significantly more frequently RF positive than women $(73 \% v 47 \%, \mathrm{p}<0.01)$.

The Mallya and Larsen's scores at the study onset were comparable in the seropositive and seronegative patients whether the RF was detected at baseline or one year later (table 3). However, Mallya score remained at higher level in those patients with RF at one year than in seronegative patients. Moreover, the Larsen's score, the frequency of the patients with nodules, and the proportional number of patients in ARA Functional classes III-IV were higher in patients seropositive at one year (fig 1 and table 3). Also, these patients had used higher number of SAARDs and discontinuation of treatment because of inefficacy (table 3).

Twenty eight patients turned seronegative during the first year after the institution of SAARD treatment. Their median (IQR) Larsen's score at the latest visit was 21.5 (7-50) and 9 of 28 (32\%) had reached remission. On the other hand, 14 patients turned RF positive during the first year and their corresponding 
Table 6 Correlations (Spearman) with 95\% confidence limits of disease clinical activity of $R A$, radiographic joint damage (Larsen score), and HAQ disability score at the onset of the treatment and at the end of the study in the patients with early $R A$ treated with "sawtooth" strategy for a mean of six years

\begin{tabular}{llc}
\hline & $H A Q$ score at onset $(n=134)$ & HAQ score at end $(n=130)$ \\
\hline At onset & $0.33(0.17$ to 0.48$)$ & $0.15(-0.02$ to 0.32$)$ \\
$\quad$ swollen joint count & $0.39(0.24$ to 0.52$)$ & $0.25(0.08$ to 0.40$)$ \\
$\quad$ tender joint count & $0.22(0.05$ to 0.37$)$ & $-0.00(-0.17$ to 0.17$)$ \\
ESR & $0.42(0.28$ to 0.56$)$ & $0.14(-0.03$ to 0.30$)$ \\
Mallya score & $-0.03(-0.20$ to 0.14$)$ & $0.01(-0.16$ to 0.18$)$ \\
Larsen score & $-0.23(-0.39$ to -0.06$)$ & $-0.04(-0.21$ to 0.13$)$ \\
disease duration & - & $0.32(0.15$ to 0.47$)$ \\
HAQ score & $0.31(0.15$ to 0.46$)$ & $0.51(0.37$ to 0.63$)$ \\
At the latest visit & $0.06(-0.11$ to 0.23$)$ & $0.23(0.05$ to 0.38$)$ \\
$\quad$ Larsen score & & \\
$\quad$ disease duration &
\end{tabular}

Larsen's score was 61 (38-78) and only 3 of 14 $(21 \%)$ of them were in remission.

EFFECT OF THE NUMBER OF SWOLLEN JOINTS AT BASELINE ON OUTCOME

At baseline 52 patients (37\%) had less than four swollen joints. Twenty of them (38\%) were in remission at two years while the frequency of remissions was $21 \%$ in the rest of the patients $(\mathrm{p}=0.04)$. The patients with initially lower number of swollen joints were in remission at the end of the follow up in similar frequencies as the rest of the patients ( $33 \% v 31 \%$, NS). Furthermore, patients with initially low number of swollen joints $(<4)$ had lower proportion of those with ARA Functional classes III-IV at the end compared with patients with higher number $(13 \% v 30 \%, \mathrm{p}<0.05)$. No such trend was observed for HAQ scores > $1(19 \% v 26 \%$, NS). The median (IQR) Larsen's scores in corresponding groups at the latest check up were $16(4-49)$ and $42(23-66)(\mathrm{p}<0.01)$.

EFFECT OF EARLY EROSIVENESS ON OUTCOME Joint erosions were found at the study entry and after one year in $47 \%$ and $82 \%$ of the patients, respectively. The presence of erosions at baseline had no significant influence either on the further functional outcome (HAQ score, ARA Functional class) or the development of new erosions. The respective frequencies of achieved remissions in initially non-erosive and erosive patients were $36 \%$ and $27 \%$ (NS). Neither did the values of Larsen's score or the number of used SAARDs at the latest visit differ significantly from each other in initially non-erosive and erosive patients. However, when the patients were divided into erosive and non-erosive disease at one year, more joint damage developed in erosive patients during the follow up than in the non-erosive patients (final median (IQR) Larsen's scores: 41 (17-61) v 11 (2-41), $\mathrm{p}<0.05)$, but no statistically significant difference was found in functional outcome measures (HAQ score, ARA Functional class) and the number of the patients in remission between these groups (data not shown).

PREDICTION OF STRUCTURAL JOINT DAMAGE PROGRESSION (TABLES 4 AND 5)

At the latest visit the Larsen's score of 48 patients $(34 \%)$ was more than 50 . At baseline the parameters measuring disease activity (swollen joint count, ESR, Mallya score) and functional disability (HAQ score) of these patients were statistically significantly higher than in the rest of the patients. On the other hand, the Larsen's scores at the baseline were comparable between these groups. In addition, a higher number of SAARDs were used in the treatment of the patients with extended joint destructions (table 4). In logistic regression analysis the independent variables consisted of sex, age, DR4, the presence of joint erosion at baseline, disease duration at the latest visit as well as RF and disease clinical activity (Mallya score) at onset and at one year. Only Mallya score at baseline and at one year, and RF at one year were variables of high significance with respect to the total joint destruction (table 5).

In 56 of 142 patients $(39 \%)$ the disease clinical activity (Mallya score) was diminished by 30 per cent or more during the first year on SAARD treatment. Nevertheless, in 16 of these 56 patients $(29 \%)$ the final Larsen's score exceeded 50.

PREDICTION OF FINAL REMISSION

No variable at baseline predicted reliably the patients with remission at the latest visit (data not shown).

RELATIONS OF DISEASE ACTIVITY AND EXTENT OF JOINT DESTRUCTIONS TO THE HAQ DISABILITY At the study entry HAQ disability score was not related to Larsen's damage score (table 6). In contrast, the Mallya and HAQ scores correlated statistically significantly with each other. On the other hand, at the latest assessment HAQ and Larsen's scores had achieved highly significant correlation (table 6).

\section{Discussion}

Considerable debate has focused on whether genes bearing the alleles encoding SE are associated with an unfavourable outcome of RA. ${ }^{17-19} 20222336-40$ In a cross sectional study Weyand and coworkers ${ }^{18}$ found that patients homozygous for $\mathrm{HLA}-\mathrm{DRB} 1^{\star} 04$ had more severe disease when compared with patients with either $\mathrm{DRB} 1{ }^{\star} 04 / 01$ or with only a single DRB $1{ }^{\star} 04$ allele. All their patients typed as HLA-DRB $1{ }^{\star} 04 / 04$ had also nodular disease. ${ }^{18}$ It has even been recommended that patients with early RA should be screened for HLA genotypes to guide treatment decisions. ${ }^{42}$ However, in a recent prospective study from Sweden and in cross sectional studies from Norway and Finland the value of genomic typing to select patients for early aggressive treatment remained questionable. ${ }^{20} 213641$ Our data demonstrate that the DR4 positive patients developed RA at a significantly younger age than the rest of the patients, which is in agreement with the Swedish and Norwegian findings. ${ }^{2136}$ However, our patients with DR4 had lower initial clinical disease activity in comparison with the rest of the patients. During the follow up the progression of joint structural damage or functional disability of these patients did not differ significantly from the rest of the patients. Furthermore, the development of rheumatoid nodules or severe joint destruction reflected in the number of joint replacements was not associated with the 
presence of these alleles. This study confirms the previous reports from Scandinavia and suggest that prognostic significance of SE to disease outcome in one population may not work in another. ${ }^{21} 3641$

An interesting question is whether antirheumatic treatment neutralises the contribution of genetic markers as determining the course of RA. The placebo treated white patients with DR4 epitope developed in a 48 week minocycline trial more erosions than the DR4 negative patients, but the gradient was not observed in the minocycline treated patients. ${ }^{22}$ The conflicting results in the studies of the predictive value of SEs may also be influenced by the intensity of SAARD treatment. Our patients with early RA were treated intensively with SAARDs from the beginning of the follow up. However, in contrast with an earlier report ${ }^{40}$ the SAARD treatment intensity in our patients was comparable in the patient with or without SE. Thus, our finding suggests that, rather than a marker of severity, $\mathrm{SE}$ is a marker of susceptibility contributing to the development of RA at a younger age.

Since the introduction of the RF test, RF has been considered strongly predictive for an unfavourable disease outcome. ${ }^{12}$ Nevertheless, in some studies the correlation of the presence of $\mathrm{RF}$ and the development of radiographic damage has not been shown. ${ }^{20}{ }^{43-45}$ This study clearly shows the critical importance of the disease duration at the time of RF detection as a predictor of disease progression. In our patients with very early disease and intensive SAARD treatment, RF positivity at study entry was a weak predictor of the outcome. On the other hand, the seropositivity at one year was of highly significant prognostic value.

Variations in the duration of disease and follow up of the studied populations and in the selection criteria for study inclusion are fundamental pitfalls in prognostic studies. ${ }^{124}$ Our cohort comprises 142 consecutive patients with very early RA. Although the disease duration of our patients at the latest visit was higher in cohort 1 than cohort 2 , all patients were followed up and checked up at regular intervals by the rheumatologists. Moreover, the patients were treated with SAARDs according to the "sawtooth" strategy. Thus, this study fulfils the criteria required for an adequate design to study the predictive factors of RA. ${ }^{12}{ }^{46}$

Most previous studies claim that men show a more favourable outcome than women. ${ }^{12}$ In this study both sexes were treated as actively with SAARDs, and the mean joint damage developed in parallel during the follow up in women and men. Moreover, our results indicate that in the majority of men the course of RA is favourable but in a few men it is very serious.

Older age at onset of RA has been considered to associate with a less favourable outcome but the results have been inconclusive. ${ }^{20}{ }^{38}{ }^{47-51}$ In our patients the disease activity at baseline was higher in older patients than in younger ones and the joint damage progression was more pronounced in the older patients. However, in logistic regression analysis, age was not the variable of significance to extended joint destruction.
An interesting question is "how early" we actually have to start SAARD treatment to achieve the best results by using "sawtooth" strategy. In this study the further progression of joint damage was not related to the disease duration at baseline. However, the results do not exclude the possibility that the earlier SAARD institution would be of greater benefit in the patients with shorter disease duration.

Many earlier studies have stated that the patients with several clinically active joints at baseline are those who most likely will have a progressive disease course. ${ }^{20}{ }^{48-55}$ Also in this study the high clinical disease activity at baseline was the most important single prognostic factor for the further joint destructions. On the other hand, in contrast with several earlier reports ${ }^{47-49} 56$ the presence of joint erosions at baseline had no significant influence on the further development of structural joint destruction during the follow up.

The reports of the development of functional disability of RA patients have found a poor initial functional capacity to be of predictive value for future disability. ${ }^{49}$ 57-60 This study clearly indicates that in the early phases of RA HAQ disability index and the measures of RA clinical activity correlate significantly, while HAQ disability and joint damage score do not. The result is consistent with two earlier Dutch studies, in which the number of painful joints was statistically significantly correlated to HAQ disability index..$^{59}$ At the later phases of the disease, however, HAQ disability index reaches highly significant correlation with structural joint damage index. Our result are in accordance with previous findings. ${ }^{61-63}$ Furthermore, it is important to observe that disease duration at the latest visit is one of the major variables reflecting on HAQ score.

We conclude, that from the clinical point of view, the disease outcome of an individual patient with very early RA cannot be predicted accurately enough by present means. Initially high disease clinical activity is the best marker for poor prognosis. In addition, after one year from the institution of SAARD treatment, the patients with unfavourable outcome are prone to be RF seropositive. Furthermore, in the patients treated according to "sawtooth" strategy, DR4 and SE seem to associate with a younger onset disease but not with an unfavourable outcome.

This work was supported by Muikkusäätiö, Turku University Central Hospital EVO-grant, and the Academy of Finland.

1 Kushner I. Does aggressive therapy of rheumatoid arthritis affect outcome? J Rheumatol 1989;16:1-4.

2 Wolfe F. 50 years of antirheumatic therapy: the prognosis of rheumatoid arthritis. J Rheumatol 1990;17:24-32.

3 Pincus T, Callahan LF. What is the natural history of rheumatoid arthritis? Rheum Dis Clin North Am 1993;19:12351 .

4 Luukkainen R, Kajander A, Isomäki H. Effect of gold on progression of erosions in rheumatoid arthritis. Better results with early treatment. Scand J Rheumatol 1977;6:189-92.

5 van der Heijde DMFM, van Riel PL, Nuver-Zwart IH, van de Putte LBA. Sulphasalazine versus hydroxychloroquine in rheumatoid arthritis: 3-years follow-up. Lancet 1990; in rheumat

6 Borg G, Allander E, Berg E, Brodin U, Trang L. Auranofin treatment in early rheumatoid arthritis may postpone early retirement. Results from a 2 -year double blind trial. J Rheumatol 1991;18:1015-20. 
7 Hannonen P, Möttönen T, Hakola M, Oka M. Sulfasalazine in early rheumatoid arthritis. A double blind, 48 week proin early rheumatoid arthritis. A double blind, 48 week prospective, place

8 Wilske KR, Healey LA. Remodeling the pyramid-a concept whose time has come. J Rheumatol 1989;16:565-7. 9 Fries JF. Reevaluating the therapeutic approach to rheuma-
toid arthritis: the "sawtooth" strategy. J Rheumatol $1990 ; 17: 12-15$

10 American college of rheumatology ad hoc committee on clinical guidelines: Guidelines for the management of rheumatoid arthritis. Arthritis Rheum 1996;39:713-22.

11 Masi AF, Maldonado-Cocco JA, Kaplan SB, Feigenbaum SL, Chandler RW. Prospective study of the early course of rheumatoid arthritis in young adults: Comparison of patients with and without rheumatoid factor positivity at patients with and without rheumatoid factor positivity at
entry and identification of variables correlating to outcome. entry and identification of variables correl

12 van der Heijde DM, van Riel PL, van Rijswijk MH, van de Putte LB. Influence of prognostic features on the final outcome in rheumatoid arthritis: a review of the literature. Semin Arthritis Rheum 1988;17:284-92.

13 Willkens RF. Prognostic staging for therapy of rheumatoid arthritis. Semin Arthritis Rheum 1991;21 (suppl 1):40-3.

14 Wollheim FA, Eberhardt KB. The search for laboratory measures of outcome in rheumatoid arthritis. Baillieres Clin Rheumatol 1992;6:69-93.

15 Hochberg MC. Predicting the prognosis of patients with rheumatoid arthritis: is there a crystal ball? J Rheumatol 1993;20:1265-7.

16 Furst DE. Predictors of worsening clinical variables and outcomes in rheumatoid arthritis. Rheum Dis Clin North Am 1994;20:309-19.

17 Young A, Jaraquemada D, Awad J, Festenstein H, Corbett M, Hay FC, et al. Association of HLA-DR4/Dw4 and DR2/Dw2 with radiologic changes in a prospective study of patients with rheumatoid arthritis: preferential relationship with HLA-Dw rather than HLA-DR specificities. Arthritis Rheum 1984;27:20-5.

18 Weyand CM, Hicok KC, Conn DL, Goronzy JJ. The influence of HLA-DRB1 genes on disease severity in rheumatoid arthritis. Ann Intern Med 1992;117:801-6.

19 Gough A, Faint J, Salmon M, Hassell A, Wordsworth P, Pilling D, et al. Genetic typing of patients with inflammatory arthritis at presentation can be used to predict outcome. Arthritis Rheum 1994;37:1166-70.

20 Fex E, Jonsson K, Johnson U, Eberhardt K. Development of radiographic damage during the first 5-6 yr of rheumatoid arthritis. A prospective follow-up study of a Swedish cohort. Br J Rheumatol 1996;35:1106-15.

21 Eberhardt K, Fex E, Johnson U, Wollheim FA. Associations of HLA-DRB and -DQB genes with two and five year outcome in rheumatoid arthritis. Ann Rheum Dis 1996;55: come

22 Reveille JD, Alarcon GS, Fowler SE, Pillemer SR, Neuner $\mathrm{R}$, Clegg DO, et al for the MIRA trial group. HLA-DRB1 genes and disease severity in rheumatoid arthritis. Arthritis Rheum 1996;39:1802-7.

23 Symmons DP, Ollier WE, Brennan P, Silman AJ. Should patients with recent onset rheumatoid arthritis be offered genetic screening? Ann Rheum Dis 1996;55:407-10.

24 Young A. Short term outcomes in recent onset rheumatoid arthritis. Br J Rheumatol 1995;34 (suppl 2):79-86.

25 Möttönen T, Paimela L, Ahonen J, Helve T, Hannonen P, Leirisalo-Repo M. Outcome in patients with early rheumatoid arthritis treated according to the "sawtooth" strategy. Arthritis Rheum 1996;39:996-1005.

26 Arnett FC, Edworthy SM, Bloch DA, McShane DJ, Fries $\mathrm{JF}$, Cooper NS, et al. The American Rheumatism Association 1987 revised criteria for the classification of rheumatoid arthritis. Arthritis Rheum 1988;131:315-28.

27 Möttönen TT. Prediction of erosiveness and rate of development of new erosions in early rheumatoid arthritis. Ann Rheum Dis 1988;47:648-53.

28 Paimela L, Leirisalo-Repo M, Helve T, Koskimies S. The prognostic value of HLA DR4 and B27 antigens in early rheumatoid arthritis. Scand J Rheumatol 1993:22:220-4.

29 Mallya RK, Mace BEW. The assessment of disease activity in rheumatoid arthritis using a multivariate analysis. Rheumatol Rehabil 1981;20:14-17.

30 Ritchie DM, Doyle JA, McInnes JM, Jasani MK, Dalakos TG, Grieveson P, et al. Clinical studies with an articular index for the assessment of joint tenderness in patients with rheumatoid arthritis. Q J Med 1968;37:393-406.

31 Pinals RS, Masi AT, Larsen RA. The Subcommittee for Criteria of Remission in Rheumatoid Arthritis of the American Rheumatism Association Diagnostic and Therapeutic Criteria Committee. Preliminary criteria for clinical remission in rheumatoid arthritis. Arthritis Rheum 1981, 24:1308-15.

32 Larsen A, Dale K, Eek M. Radiographic evaluation of rheumatoid arthritis and related conditions by standard reference films. Acta Radiol Diagn (Stockh) 1977;18:48191.

33 Steinbrocker O, Traeger CH, Battermann RC. Therapeutic criteria in rheumatoid arthritis. JAMA 1949;140:659-62.

34 Fries JF, Spitz P, Kraines RG, Holman HR. Measurement of patient outcome in arthritis. Arthritis Rheum 1980;23: $137-45$.

35 Ilonen J, Lagerstedt A, Koskimies S, Reunanen $M$. HLA-Dw1 and BfF1 as protective markers in multiple sclerosis. J Neuroimmunol 1983;5:283-8.
36 Gran JT, Husby G, Thorsby E. The association between

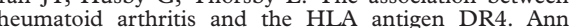
Rheum Dis 1983;42:292-6.

37 Silman AJ, Reeback J, Jaraquemada D. HLA-DR4 as a predictor of outcome three years after onset of rheumatoid arthritis. Rheumatol Int 1986;6:233-5.

38 van der Heijde DMFM, van Riel PLCM, van Leeuwen MA, van't Hof MA, van Rijswijk MH, van de Putte LBA. Prognostic factors for radiographic damage and physical disability in early rheumatoid arthritis. A Prospective follow-up study of 147 patients. Br J Rheumatol 1992;31: 519-25

39 Calin A, Elswood J, Klouda PT. Destructive arthritis rheumatoid factor, and HLA-DR4: susceptibility versus severity,

40 van Zeben D, Hazes JMW, Zwinderman AH, Cats A, Schreuder GMT, D'amaro J, et al. Association of HLA-DR4 with a more progressive disease course in patients with rheumatoid arthritis. Arthritis Rheum 1991; 34:822-30.

41 Hakala M, Silvennoinen-Kassinen S, Ikäheimo I, Isosomppi , Tiilikainen A. HLA markers in a community-based rheumatoid arthritis series. Ann Med 1997;29:291-6.

42 Emery P, Salmon M. Early rheumatoid arthritis: time to aim for remission? Ann Rheum Dis 1995;54:944-7.

43 Amos RS, Constable TJ, Crockson RA, McConkey B. Rheumatoid arthritis: relation of serum C-reactive protein and erythrocyte sedimentation rates to radiographic changes. BMJ 1977;1:195-7

44 Dawes PT, Fowler PD, Jackson R, Collins M, Shadwoth $\mathrm{MF}$, Stone $\mathrm{R}$, et al. Prediction of progressive joint damage in patients with rheumatoid arthritis receiving gold or d-penisillamine therapy. Ann Rheum Dis 1986;45:945-9.

5 Westedt ML, Serum immune complexes containing IgA appear to
predict erosive arthritis in a longitudinal study in rheumatoid arthritis. Ann Rheum Dis 1986;45:809-15.

46 Young A, van der Heijde DMFM. Can we predict aggressive disease? Bailliers Clin Rheumatol 1997;11:27-48.

47 Luukkainen R, Kaarela K, Isomäki H, Martio J, Kiviniemi P. The prediction of radiological destruction during the early stage of rheumatoid arthritis. Clin Expl Rheumatol 1983;1:295-8

48 Kaarela K. Prognostic factors and diagnostic criteria in early rheumatoid arthritis. Scand J Rheumatol 1985;14 (suppl 57): $1-54$.

49 Sherrer YS, Bloch DA, Mitchell DM, Young DY, Fries JF. The development of disability in rheumatoid arthritis. Arthritis Rheum 1986;29:494-500.

50 Scott DL, Coulton BL, Symmons D, Popert A. Long-term outcome of treating rheumatoid arthritis: Results after 20 years. Lancet 1987; i:1108-11.

51 van Schaardenburg D, Hazes JM, de Boers A, Zwinderman AH, Meijers KA, Breedveld FC. Outcome of rheumatoid arthritis in relation to age and rheumatoid factor at diagnosis. J Rheumatol 1993;20:45-52.

52 Young A, Corbett M, Winfield J, Jaqueremanda D, Williams P, Papasavvas G, et al. A prognostic index for erosive changes in the hands, feet, and cervical spines in early rheumatoid arthritis. Br J Rheumatol 1988;27:94-101.

53 van der Heijde DMFM, van Leeuwen MA, van Riel PLCM, Koster AM, van't Hof MA, van Rijswijk $\mathrm{MH}$, et al. Biannual radiographic assessments of hands and feet in a three-year prospective followup of patients with early rheumatoid arthritis. Arthritis Rheum 1992;35:26-34.

54 van Zeben D, Hazes JMW, Zwinderman AH, Vandenbroucke JP, Breedveld FC. Factors predicting outcome of rheumatoid arthritis: results of a followup study. J Rheumatol 1993;20:1288-96.

55 van Leeuwen MA, van der Heijde DMFM, van Rijswijk MH, Houtman PM, van Riel PLCM, van de Putte LBA, et al. Interrelationship of outcome measures and process variables in early rheumatoid arthritis. A comparison of radiologic damage, physical disability, joint counts, and acute phase reactants. J Rheumatol 1994;21:425-9.

56 Fleming A, Crown JM, Corbett M. Prognostic value of early features in rheumatoid disease. BMJ 1976;1:1243-5.

57 Jacoby RK, Jayson MIV, Cosh JA. Onset, early stages, and prognosis of rheumatoid arthritis: a clinical study of 100 patients with 11-year follow-up. BMJ 1973;2:96-100.

58 Eberhardt KB, Rydgren LC, Petterson H, Wollheim FA. Early rheumatoid arthritis: onset, course, and outcome over 2 years. Rheumatol Int 1990;10:135-42.

59 van der Heide A, Jacobs JWG, Haanen HCM, Bijlsma JWJ. Is it possible to predict the first year extent of pain and disability for patients with rheumatoid arthritis? J Rheumatol 1995;22:1466-70

60 Harrison BJ, Symmons DPM, Brenman P, Bankhead CR, Barrett EM, Scott DGI, et al. Inflammatory polyarthritis in the community is not a benign disease: Predicting functional disability one year after presentation. J Rheumatol 1996;23:1326-31.

61 Fuchs HA, Callahan LF, Kaye JJ, Brooks RH, Nance EP, Pincus T. Radiographic and joint count findings of the hand in rheumatoid arthritis. Arthritis Rheum 1988;31:44-51.

62 Kaarela K, Sarna S. Correlation between clinical facets of outcome in rheumatoid arthritis. Clin Exp Rheumatol 1993;11:643-4.

63 Hakala M, Nieminen P, Manelius J. Joint impairment is strongly correlated with disability measured by self-report questionnaires. Functional status assessment of individuals with rheumatoid arthritis in a population based series. J Rheumatol 1993;21:64-9. 